TRATADO SOBRE EL ACUERDO DEFINITIVO CON RESPECTO A ALEMANIA 

$-$ 
Revista de Derecho Político, núm. 40, 1995, pp. 231-239

\section{TRATADO SOBRE EL ACUERDO DEFINITIVO CON RESPECTO A ALEMANIA}

La República Federal de Alemania, la República Democrática Alemana, los Estados Unidos de América, el Reino Unido de Gran Bretaña e Irlanda del Norte, la República Francesa y la Unión de la Repúblicas Socialistas Soviéticas,

Conscientes de que sus pueblos conviven en paz desde 1945,

Teniendo en cuenta los históricos cambios operados recientemente en Europa, que permiten superar la división del continente,

Tomando en consideración los derechos y responsabilidades de las Cuatro Potencias con respecto a Berlín y Alemania en su conjunto y los acuerdos y decisiones correspondientes de las Cuatro Potencias del tiempo de la guerra y de la posguerra,

Resueltos, en concordancia con sus obligaciones derivadas de la Carta de las Naciones Unidas, a desarrollar entre las naciones relaciones amistosas fundadas sobre el respeto del principio de igualdad de derechos y autodeterminación de los pueblos, y a adoptar otras medidas apropiadas para consolidar la paz mundial,

Recordando los principios del Acta Final de la Conferencia sobre la Seguridad y la Cooperación en Europa, firmada en Helsinki,

Reconociendo que tales principios han sentado sólidas bases para la construcción de un orden de país justo y duradero en Europa, da uno,

Determinados a tener en cuenta los intereses de seguridad de ca- 
Convencidos de la necesidad de superar definitivamente los antagonismos y desarrollar la cooperación en Europa,

Confirmando su disposición a fortalecer la seguridad, en particular adoptando medidas eficaces de control de armamentos, desarme y fomento de la confianza; su voluntad de no considerarse mutuamente adversarios, sino de coadyuvar a una relación de confianza y cooperación; y en consecuencia su disposición a considerar positivamente la adopción de medidas institucionales apropiadas en el marco de la Conferencia sobre la Seguridad y la Cooperación en Europa,

Celebrando el hecho de que el pueblo alemán, ejerciendo libremente su derecho a la autodeterminación, ha expresado su voluntad de establecer la unidad estatal de Alemania para servir a la paz del mundo como miembro igual y soberano de una Europa unida,

Convencidos de que la unificación de Alemania en cuanto Estado con fronteras definitivas constituye un significativo aporte a la paz y a la estabilidad en Europa, Alemania,

Con el propósito de concertar el acuerdo definitivo con respecto a

Reconociendo que de este modo y a través de la unificación de Alemania en cuanto Estado democrático y pacífico pierden su función los derechos y responsabilidades de las Cuatro Potencias relativos a Berlín y a Alemania en su conjunto,

Representados por sus Ministros de Asuntos Exteriores, quienes de conformidad con la declaración adoptada en Ottawa el 13 de febrero te 1990 se reunieron en Bonn el 5 de mayo de 1990, en Berlín el 22 de junio de 1990, en París el 17 de julio de 1990 con la participación del Ministro de Relaciones Exteriores de la República de Polonia, y en Moscú el 12 de septiembre de 1990,

han convenido en lo siguiente:

\section{Artículo 1}

1. La Alemania unida comprenderá el territorio de la República Federal de Alemania, la República Democrática Alemana y todo Berlín. Sus fronteras exteriores serán las fronteras de la República Federal de Alemania y de la República Democrática Alemana y serán definitivas a partir de la fecha de entrada en vigor del presente tratado. La confirma- 
ción del carácter definitivo de las fronteras de la Alemania unida constituye un elemento esencial del orden de paz en Europa.

2. La Alemania unida y la República de Polonia confirmarán la frontera existente entre ellos en un tratado vinculante a efectos del Derecho Internacional.

3. La Alemania unida no tiene reivindicación territorial alguna contra otros Estados, ni formulará ninguna en el futuro.

4. Los Gobiernos de la República Federal de Alemania y de la República Democrática Alemana asegurarán que la constitución de la Alemania unida no contendrá ninguna disposición incompatible con estos principios. Lo anterior es aplicable en consecuencia a las disposiciones contenidas en el preámbulo y en los artículos 23, frase segunda, y 46 de la Ley Fundamental de la República Federal de Alemania.

5. Los Gobiernos de los Estados Unidos de América, el Reino Unido de Gran Bretaña e Irlanda del Norte, la República Francesa y la Unión de Repúblicas Socialistas Soviéticas toman formalmente nota de los compromisos y declaraciones correspondientes de los Gobiernos de la República Federal de Alemania y de la República Democrática Alemana, y declaran que su puesta en práctica confirmará el carácter definitivo de las fronteras de la Alemania unida.

\section{Artículo 2}

Los Gobiernos de la República Federal de Alemania y de la República Democrática Alemana reafirman sus declaraciones de que sólo la paz emanará de suelo alemán. Con arreglo a la constitución de la Alemania unida, los actos susceptibles de perturbar las relaciones pacíficas entre las naciones y realizados con tal intención, especialmente para preparar una guerra de agresión, son anticonstitucionales y punibles. Los Gobiernos de la República Federal de Alemania y de la República Democrática Alemana declaran que la Alemania unida no empleará jamás ninguna de sus armas, excepto en concordancia con su constitución y la Carta de las Naciones Unidas.

\section{Artículo 3}

1. Los Gobiernos de la República Federal de Alemania y de la República Democrática Alemana reafirman su renuncia a la fabricación, a la posesión y al control de armas nucleares, biológicas y químicas. Decla- 
ran que también la Alemania unida respetará estos compromisos. En particular, continuarán aplicándose a la Alemania unida los derechos y obligaciones derivados del Tratado sobre la No Proliferación de Armas Nucleares, de 1 de julio de 1968.

2. El Gobierno de la República Federal de Alemania, plenamente de acuerdo con el Gobierno de la República Democrática Alemana, declaró el 30 de agosto de 1990 en Viena lo siguiente con ocasión de las negociaciones sobre las fuerzas armadas convencionales en Europa:

«El Gobierno de la República Federal de Alemania se obliga a reducir en un plazo de tres a cuatro años sus efectivos a 370.000 hombres (fuerzas terrestres, aéreas y navales). Esta reducción comenzará al entrar en vigor el primer tratado FOC. Dentro de los términos de este techo global, un máximo de 345.000 hombres pertenecerá a las fuerzas terrestres y aéreas, que, conforme al mandato acordado, son las únicas objeto de las negociaciones sobre las fuerzas armadas convencionales en Europa. Entiende que en las negociaciones de continuidad los demás participantes en las negociaciones contribuirán a su vez a fortalecer la seguridad y la estabilidad en Europa, incluyendo medidas de limitación de los efectivos."

El Gobierno de la República Democrática Alemana se ha adherido expresamente a esta declaración.

3. Los Gobiernos de los Estados Unidos de América, el Reino Unido de Gran Bretaña e Irlanda del Norte, la República Francesa y la Unión de las Repúblicas Socialistas Soviéticas toman nota de estas declaraciones de los Gobiernos de la República Federal de Alemania y de la República Democrática Alemana.

\section{Articulo 4}

1. Los Gobiernos de la República Federal de Alemania, la República Democrática Alemana y la Unión de las Repúblicas Socialistas Soviéticas declaran que la Alemania unida y la Unión de Repúblicas Socialistas Soviéticas regularán mediante tratado las condiciones y la duración de la presencia de fuerzas armadas soviéticas en el territorio de la actual República Democrática Alemana y de Berlín, así como el desarrollo de la retirada de dichas fuerzas armadas, que habrá terminado al final del año 1994, en relación con el cumplimiento del compromiso de los Gobiernos de la República Federal de Alemania y de la República Democrática Alemana a que se refiere el párrafo 2 del artículo 3 del presente Tratado. 
2. Los Gobiernos de los Estados Unidos de América, el Reino Unido de Gran Bretaña e Irlanda del Norte y la República Francesa toman nota de esta declaración.

\section{Artículo 5}

1. Hasta la culminación de la retirada de las fuerzas armadas soviéticas del territorio de la actual República Democrática Alemana y de Berlín conforme al artículo 4 del presente Tratado, sólo estarán estacionadas en este territorio, en calidad de fuerzas armadas de la Alemania unida, unidades alemanas de defensa territorial no integradas en las estructuras de alianza a las cuales están adscritas las fuerzas armadas alemanas en el resto del territorio alemán. Durante dicho período, y sin perjuicio de lo dispuesto en el párrafo 2 del presente artículo, no serán estacionadas en este territorio ni realizarán ninguna otra actividad militar fuerzas armadas de otros Estados.

2. Durante la presencia de las fuerzas armadas soviéticas en el territorio de la actual República Democrática Alemana y de Berlín, permanecerán estacionadas en Berlín, a petición de la parte alemana, fuerzas armadas de los Estados Unidos de América, el Reino Unido de Gran Bretaña e Irlanda del Norte y la República Francesa, por acuerdo al efecto entre el Gobierno de la Alemania unida y los Gobiernos de los Estados concernidos. El nivel de efectivos y de equipamiento de todas las fuerzas armadas no alemanas estacionadas en Berlín no será mayor que en el momento de la firma del presente Tratado. Las fuerzas armadas no alemanas no introducirán ahí nuevas categorías de armas. El Gobierno de la Alemania unida concertará con los Gobiernos de los Estados que tienen fuerzas armadas estacionadas en Berlín tratados mediante los cuales se fijarán condiciones justas teniendo en cuenta las relaciones existentes con los Estados concernidos.

3. Tras la culminación de la retirada de las fuerzas armadas soviéticas del territorio de la actual República Democrática Alemana y de Berlín, podrán estacionarse en esta parte de Alemania también unidades de las fuerzas armadas alemanas adscritas a las estructuras militares de alianza de la misma manera que las unidades estacionadas en el resto del territorio alemán, si bien sin vectores de armas nucleares. Esto no se aplica a los sistemas de armas convencionales que puedan tener otras capacidades aparte de las convencionales pero que, en esta parte de Alemania, estén equipados para fines convencionales y destinados exclusivamente a dichos fines. No serán estacionadas ni desplegadas en esta parte de Alemania fuerzas armadas ni armas nucleares extranjeras, ni tampoco vectores de tales armas. 
Artículo 6

El derecho de la Alemania unida de pertenecer a alianzas, con todos los derechos y responsabilidades que de ello se derivan, no queda afectado por el presente Tratado.

\section{Artículo 7}

1. Los Estados Unidos de América, el Reino Unido de Gran Bretaña e Irlanda del Norte, la República Francesa y la Unión de Repúblicas Socialistas Soviéticas ponen fin mediante el presente tratado a sus derechos y responsabilidades con respecto a Berlín y a Alemania en su conjunto. En consecuencia, se pone fin a los acuerdos, decisiones y prácticas cuatripartitas correspondientes y se disuelven todas las instituciones respectivas de las Cuatro Potencias.

2. La Alemania unida gozará por consiguiente de plena soberanía sobre sus asuntos internos y exteriores.

\section{Artículo 8}

1. El presente Tratado será sometido a ratificación o aceptación lo antes posible. Por parte alemana, la ratificación será efectuada por la Alemania unida. El tratado se aplicará en consecuencia a la Alemania unida.

2. Los instrumentos de ratificación o aceptación serán depositados en poder del Gobierno de la Alemania unida. Ésta informará a los Gobiernos de las otras partes contratantes del depósito de cada instrumento de ratificación o aceptación.

\section{Artículo 9}

El presente Tratado entrará en vigor para la Alemania unida, los Estados Unidos de América, el Reino Unido de Gran Bretaña e Irlanda del Norte, la República Francesa y la Unión de Repúblicas Socialistas Soviéticas en la fecha del depósito del último instrumento de ratificación o aceptación por estos Estados. 
Artículo 10

El original del presente Tratado, cuyos textos alemán, francés, inglés y ruso son igualmente auténticos, será depositado en poder del Gobierno de la República Federal de Alemania, que remitirá copia certificada a los Gobiernos de las otras Partes Contratantes.

En testimonio de lo cual, los plenipotenciarios infrascritos, debidamente autorizados al efecto, han firmado el presente Tratado.

Hecho en Moscú, el 12 de septiembre de 1990.

Por la República Federal de Alemania

Por la República Democrática Alemana

Por la República Francesa

Por la Unión de Repúblicas Socialistas Soviéticas

Por el Reino Unido de Gran Bretaña e Irlanda del Norte

Por los Estados Unidos de América

Minuta acordada en relación con el Tratado sobre el acuerdo definitivo con respecto a Alemania del 12 de septiembre de 1990.

Todas las cuestiones relacionadas con la aplicación de la palabra "desplegadas", tal y como aparece empleada en la última frase del párrafo 3 del artículo 5, serán decididas por el Gobierno de la Alemania unida de forma razonable y responsable teniendo en cuenta los intereses de seguridad de cada Parte Contratante tal y como queda establecido en el preámbulo. 